\title{
Transforming sustainable food and waste behaviors by realigning domains of knowledge in our education system
}

Erin Redman, $\mathrm{PhD}^{\mathrm{a}}$ **

Aaron Redman ${ }^{\mathrm{b}}$

a School of Sustainability, Arizona State University, PO Box 875502, Tempe, AZ 85287-5502

b Escuela Nacional de Estudios Superiores-UNAM, Unidad León, Boulevard UNAM, Col. Predio el Saucillo y el Potrero 2011, CP. 36969, Guanajuato, México

*Corresponding Author +01 (480) 840-5838

E-mail addresses: erin.frisk@asu.edu (E. Redman); aaron.redman@enes.unam.mx (A. Redman)

Word Count (including table captions): 6,340

Keywords: sustainability education; sustainable behaviors; pro-environmental behaviors; knowledge domains; K-12 teachers

(C) 2013. This manuscript version is made available under the CC-BY-NC-ND 4.0 license http://creativecommons.org/licenses/by-nc-nd/4.0/ 


\section{Transforming sustainable food and waste behaviors by realigning domains of knowledge in our education system}

\section{Introduction}

Sustainability advocates widely recognize that many consumer behaviors will need to change in order for society to achieve a sustainability transition that will meet human needs, reduce social inequities and maintain the natural resources necessary to support human life on Earth (Heller \& Keoleian, 2003; Leiserowitz et al., 2005). Prominent behavior researcher, Paul Stern, suggests that "changing environmentally significant consumer behavior" is critical for an array of policy decisions and interventions, including the introduction of new and beneficial technology, modifications of institutional structures, and for changing material or financial incentives (Stern, 1999, p. 461). Through this research we focus on consumer behaviors as they relate to sustainable food and waste strategies. Food and waste systems are embedded within a complex array of political, technological, and institutional structures, yet, it has been seen that individual consumer demand and purchasing power can, overtime, impact these structures and promote change throughout the production, consumption, and disposal phases (Heller \& Keoleian, 2003). One such example of consumer behaviors impacting political change and production processes is the consumer boycott of tuna that led to the 1990 US legislation creating the "Dolphin Safe" tuna label (Wright, 2000). A number of other researchers have also concluded that one of the most effective strategies for enhancing the sustainability of the U.S. food system (including waste and disposal processes) exists in changing consumer behavior (Heller \& Keoleian, 2003; Stagl, 2002).

While other researchers have clearly established the importance of targeting individuals' behaviors in order to create sustainable change, diffusion of many sustainable practices and behaviors 
has yet to take-off; in part due to erroneous assumptions about how change occurs (McKenzie-Mohr, 2000; Rogers, 2003). First, some researchers are influenced by an innovation bias and implicitly assume that a great new idea, practice, or technology will inevitably diffuse throughout most of society on its own because it is cleaner, healthier, safer, more efficient, and/or more sustainable (Rogers, 2003). Separately, there are others that recognize individual behaviors as a central part of creating collective change but proceed on the faulty assumption that simply providing information (e.g., through marketing, labeling, or education) will foster the targeted behavior change (Kollmuss \& Agyeman, 2002; Monroe, 2003; Pooley \& O’Connor, 2000b; Simmons \& Volk, 2002). This research, on the other hand, proceeds on the notion that creating a more sustainable product, idea, or practice and providing information regarding said product will not, on its own, lead to the desired collective change. Rather we should understand what motivates or constrains individual behaviors and create programs that move beyond information in order to target the predictors of behavior.

In targeting the adoption of specific behaviors, many scholars and practitioners have turned to education as a pivotal tool in creating long-term change (Kelder, et al., 1994; Luepker et al., 1983). There are a number of fields with which to draw from regarding the relationship between education and behavior modification (health, drug, smoking, and anti-violence programs to name a few). We focus on environmental education literature, in part, due to the parallels often drawn between sustainability and environmental education — although sustainability is a distinct departure from environmental education and the associated nature-centric points of view. For decades the primary goal of environmental education has been to foster pro-environmental behaviors (Hungerford \& Volk, 1990; Monroe, 2003; Pooley \& O’Connor, 2000b; Ramsey, 1993). However, as education psychologists, Pooley and O’Conner note, "The main focus of environmental education programs has been to change environmental behavior through increasing environmental knowledge" (2000, p. 711). This focus on 
environmental (declarative) information as the means for targeting behaviors has been termed the Information-Deficit Model (e.g., students just need to understand the environment and then they will behave in a pro-environmental manner). This simplistic, linear approach to behavior change has been found to be inadequate in addressing the motivators and impediments to changing behaviors (Kollmuss \& Agyeman, 2002; Monroe, 2003; Pooley \& O'Connor, 2000b). Therefore, this research looks beyond information as a predictor of behavior in order to explore diverse, dynamic and often subjective ways of knowing that influence participation in sustainable food and waste practices amongst K-12 educators (see section 1.2 for details on the selection of our target population).

While this article focuses on a select number of sustainable behaviors, the incorporation of multiple forms of knowledge has broader implications for all sustainability education. First, we emphasize that sustainability knowledge is not confined to scientific information or codified facts; rather it incorporates subjective ways of knowing that allow for diverse values and perspectives. In order to educate for sustainability in a way that integrates different ways of knowing, pedagogical approaches must also become more reflexive, integrative, and collaborative (Dupuis \& Ball, 2013). Hence, the approach taken here also suggests a need to depart from didactic pedagogies in which an expert disseminates facts to passive recipients. Previous research has linked the knowledge domains to an array of innovative pedagogy, including real-world, experiential, problem-based, and collaborative methods, in order to emphasize social learning processes (Redman, 2013). To effectively integrate this approach into classrooms and schools, a shift away from traditional, positivistic views of science needs to occur. If universities can embrace a change to post-normal science, teachers whom receive their training at universities will become aquatinted with science through this more participatory, normative and inclusive approach that acknowledges multiple ways of knowing (Funtowicz \& Ravetz, 2003). 


\subsection{Knowledge Domains}

In order to move away from the Information-Deficit Model of behavior change, this research drew on behavioral theories and related studies in order to inform the relationship between education and action. While behavior scientists have proposed a variety of useful frameworks for explaining individual action, we chose to use a framework proposed by Kaiser and Fuhrer (2003) that centers on four different domains of knowledge as an organizational tool: declarative (factual/technical socioecological information), procedural (how-to information and skills), effectiveness (subjective understanding of impacts/efficacy), and social (subjective understanding of normative trends and social expectations) (Redman, 2013; Kaiser \& Fuhrer 2003). While the knowledge domains are insufficient individually to entirely explain the motivations behind people's actions, they collectively provide an overarching framework for integrating an array of behavioral theories (Frisk \& Larson, 2011). The approach to the knowledge domains taken here expands beyond the traditional views of knowledge in order to include the subjective and dynamic processing of our environment as a form of knowledge. In this manner, we have integrated concepts about values, norms, attitudes and beliefs developed by other behavioral scholars into the domain constructs (Ajzen, 1985; Cialdini, Reno, \& Kallgren, 1990; Stern, 2000). Below we briefly define each domain as they relate to various schools of thought regarding environmentally responsible behaviors.

Declarative knowledge typically addresses how environmental systems operate in factual, technical, mechanical or biophysical terms, such as information about the ecological structure, functioning of ecosystems, and social-ecological interactions (Kaiser \& Fuhrer, 2003). Although research has suggested that this is the least effective type of knowledge in promoting pro-environmental behaviors, most educators focus on disseminating declarative knowledge (Pooley \& O’Connor, 2000a; Simmons \& Volk, 2002). Declarative knowledge is emphasized in the Information-Deficit Model 
(IDM), whereby in a straightforward, linear fashion, environmental knowledge is expected to lead to awareness and concern, and ultimately, to pro-environmental behaviors (Kollmuss \& Agyeman, 2002). Psychologists and others have since refuted this simplistic model, noting that changing behavior is very difficult and information is simply not enough to spur the change itself (Kollmus \& Agyeman, 2002).

Procedural knowledge refers to process knowledge and how-to skills—-such as how to sort garbage into recyclables and non-recyclables for proper disposal (Kaiser \& Fuhrer, 2003; Monroe, 2003). Certain forms of procedural knowledge have been effective in promoting behavior change; for instance, information about how to participate in decision-making processes is a strong predictor of political engagement (Kaiser \& Fuhrer, 2003). Procedural information provides answers to questions such as, 'where do I vote?' or 'how do I register?' but not value-laden questions such as 'what is the significance of my vote?' Procedural knowledge correlates closely with situational and structural factors that facilitate or constrain action (i.e. the presence or absence of a curbside recycling program impacts the how-to's of recycling) and appears to be most effective in fostering behavior change when that knowledge is gained through experience and action (Redman, 2013).

Effectiveness, or impact, knowledge addresses the awareness of consequences associated with different behaviors, essentially answering the question, 'is the behavioral sacrifice worthwhile?' (Kaiser \& Fuhrer, 2003; Monroe, 2003). Stern's (2000) Value-Belief-Norm (VBN) model of pro-ecological behavior highlights two key behavioral determinants pertinent to effectiveness knowledge; the first is the perceived consequences of behaviors, and the second is beliefs about who is responsible for environmental outcomes. The latter correlates to a person's "locus of control," which represents the confidence individuals have in their ability to bring about impactful change through their personal actions (Kollmuss \& Agyeman, 2002; Monroe, 2003). Effectiveness knowledge influences behaviors through people's perceptions about how or even if their behaviors really impact the environment or 
others. As such, they are closely correlated to subjective beliefs and attitudes which are subject to change over time and are likely to vary due to local influences (Kaiser \& Fuhrer, 2003; Monroe, 2003). For example, if an individual believes that recycling is not an energy efficient means of waste management, their negative perception about the effectiveness of that action may deter them from recycling (Tucker \& Speirs, 2003).

Social knowledge encompasses knowledge regarding the motives, intentions, and actions of other people (Kollmuss \& Agyeman, 2002). Social knowledge embodies what is typically described as social norms by behavioral scientists (Stern, 2000; Trumbo \& O'Keefe, 2001). Kaiser and Fuhrer (2003) use social knowledge to explain two types of norms; conventional norms refer to customs, traditions, and expectations associated with the need for social approval, while moral norms refer to the value or importance a person places on equity, human welfare, environmental impacts or other behavioral outcomes. Schultz et al. (2007) further distinguish between different types of norms; descriptive norms refer to perceptions of what is commonly done, whereas injunctive norms refer to what is approved or disapproved by others. Changing the perception of what society approves or views as desirable has been the subject of much research and hundreds of marketing campaigns, ranging from smoking ads to recycling campaigns (McKenzie-Mohr, 2011). The importance of social knowledge as a predictor of behavior is especially critical in a normative field such as sustainability, where societal values are central in guiding what we ought to sustain and how. Classrooms provide an ideal environment for fostering sustainable social norms because of the many opportunities teachers have for modeling and positively reinforcing sustainable behaviors.

Academic studies rarely address more than two of these knowledge domains, typically declarative and procedural, while education programs generally focus solely on declarative, ecological knowledge. Although Kaiser and Fuhrer hypothesize that the convergence of all four domains of 
knowledge will lead to sustained pro-environmental behaviors, the collective effect of the knowledge domains on sustainable behaviors has yet to be empirically assessed (Kaiser \& Fuhrer, 2003). Our hypothesis builds off the insights or Kaiser and Fuhrer regarding the ineffectiveness of technical, ecological information while empirically exploring all four domains of knowledge. We hypothesize that an individual with more procedural, effectiveness and social knowledge about a sustainability area (e.g. waste) will participate in more sustainable behaviors in that area more frequently. On the other hand, having more declarative knowledge about that area will not make the individual more likely to engage in sustainable behaviors. Our survey is the first empirical study to quantitatively assess the four domains of knowledge as predictors of sustainable food and waste behaviors.

\subsection{Selection of Teachers as Target Population}

K-12 education is being increasingly seen as a critical environment for building capacity for transformative change towards sustainability (Nolet, 2009; Simmons \& Volk, 2002; Sterling, 2001). One of the reasons to focus on K-12 education is due to the vast number of people- 60 million Americansthat spend their time at K-12 schools (Freeman, 2013). Additionally, education has often been cited as central to equipping future generations with the knowledge, skills, and behaviors necessary to cope with our sustainability challenges (Cortese, 2003; Orr, 1991; Pooley \& O’Connor, 2000b; Rowe, 2007). Within schools, teachers are ideally positioned as role models for future generations and have the capacity to reach a younger population that has yet to become too entrenched and cemented in their habits and behaviors to change (Kelder, et al., 1994).

Currently, few educators incorporate action and change as a component of their teaching or classroom practices (Moore, 2005; Stir, 2006). One barrier to integrating sustainability practices into the classroom is a lack of deep knowledge among teachers regarding sustainable behaviors (Nolet, 2009). While research indicates that educators have adequate surface knowledge (i.e., declarative 
knowledge), they tend to neglect practical skills (i.e., procedural knowledge) and action as part of sustainability education (Nolet, 2009; Stir, 2006). Through our survey of future and current K-12 teachers across the United States described here, we sought to understand where knowledge (and of what types) is most lacking and how the presence or absence of different types of knowledge impacts participation in sustainable behaviors. The results of this research can inform approaches to teacher education so that they better target gaps in knowledge and behaviors with the ultimate goal of promoting pro-sustainability behaviors and supporting teachers as social agents of change.

The basis for empirically assessing the relationship between knowledge in the four domains and associated behaviors amongst teachers, in part, stems from the success (measured in terms of behavior change) of an education program that targeted the four knowledge domains through novel pedagogical approaches. A recent publication by Redman (2013) details the education practices implemented and the associated changes in knowledge and behaviors amongst the student participants. In addition to the impacts this approach had upon the students (outlined in Redman, 2013), there were also three K-12 teachers involved in the program as part of their Masters degrees in science education. Prior to participating in the education program, the teachers reported low-levels of knowledge regarding food and waste sustainability and paid little credence to the importance of modeling and positively reinforcing sustainable behaviors or setting sustainable norms in the classroom. In the follow-up interviews and surveys the teachers detailed how the action-oriented, hands-on approach to knowledge acquisition changed their personal food and waste behaviors as well as prompted them to implement more sustainable practices in their classrooms. The findings gathered through the previously conducted qualitative work provided a basis for proposing our hypothesis regarding the relationship between the four knowledge domains and food and waste behaviors. 


\subsection{Selection of Food and Waste Behaviors}

There is mounting evidence suggesting that the actions promoted and propagated by our industrialized society could destroy the health and well-being of our planet and many of the efforts to counteract this are focusing on changing people's patterns of consumption and disposal in order to transition towards a more sustainable society (Cortese, 2003; Kates \& Parris, 2003; McKenzie-Mohr, 2000; Monroe, 2003; Zelezny, 1999). This research focuses on a select number of food and waste behaviors in order to understand the relationship between different ways of knowing and participation in sustainability-related activities. However, it is critical to note that sustainable solutions are neither fixed nor prescribed. In the face of complexity and uncertainty, we acknowledge that the behaviors selected for study are not without their trade-offs and we do not propose them as perfect solutions to the many wicked sustainability challenges. Rather, we must muddle through and attempt to make progress in understanding how individuals can contribute to collective change for sustainability.

A number of researchers have established that consumer behavior and dietary habits have a significant impact on agricultural production, distribution and the nature of our food options (Heller \& Keoleian, 2003). The benefits of changing food consumption and purchasing behavior ripples out through the food life cycle, resulting in a multiplying effect that impacts energy, materials, and the environment as well as human health and well-being (Heller \& Keoleian, 2003). We narrowed our focus to a few specific behaviors that were selected because of their action-ability at an individual scale and prevalence in the food sustainability literature. Our survey focused on the following sustainable food behaviors: 1.) reduced meat consumption, 2.) purchasing of organic foods, 3.) purchasing of local products from farmer's markets, 4.) consumption of whole foods rather than processed ones.

Changing people's purchasing and disposal behaviors in order to reduce the amount of waste created and sent to landfills has been the focus of a number of studies (Barr et al., 2005; Joseph, 2006; 
McKenzie-Mohr, 2011). Our current, mostly linear (meaning not closed loop), waste system squanders valuable resources (both energy and materials) and creates health, environmental and economic problems. In this study, we focused on widely accepted and researched sustainable waste strategies: 1.) reduce waste produced by the individual, 2.) choose reusable products over disposables (i.e., single-use products), and 3.) engage in waste recovery practices (i.e., recycling and composting). Each of these behaviors diverts waste from landfills which is one of the principal goals of a sustainable waste system. Additionally, reducing the consumption of single-use products through reuse and reduce strategies impacts energy input in production and distribution phases, hence linking waste strategies with broader discussions on promoting environmentally conscious consumerism (Eriksson et al., 2005).

\section{Methods}

\subsection{Survey Design}

As discussed in section 1.3 we chose to focus this study on just two sustainability-related areas, food and waste. To do so, two separate surveys were created one focusing on each area (further details on survey design can be found in Appendix A). Table 1 illustrates the question formats and response scales utilized (a complete list of questions sorted by knowledge domain can be found in Appendix A).

\section{Table1.}

Question format and associated response scales

\begin{tabular}{|l|l|}
\hline \multicolumn{1}{|c|}{ Question Format } & \multicolumn{1}{|c|}{ 5-Point Response Scales } \\
\hline $\begin{array}{l}\text { How familiar are you with the following terms and } \\
\text { concepts }\end{array}$ & 'Never heard of' to 'Heard of \& know a lot about' \\
\hline How would you rate your knowledge about & 'Poor' to 'Excellent' \\
\hline How would you rate your ability to & 'Poor' to 'Excellent' \\
\hline How would you rate your awareness of & 'Poor' to 'Excellent' \\
\hline $\begin{array}{l}\text { How would you rate your agreement with the } \\
\text { following statements }\end{array}$ & 'Strongly agree' to 'Strongly disagree' \\
\hline $\begin{array}{l}\text { Over the last year, how often have you made the } \\
\text { following choices }\end{array}$ & 'Never (not at all)' to 'Always $(>90 \%$ of the time)' \\
\hline
\end{tabular}


The survey was pilot-tested with different audiences and was checked for content validity by experts in sustainability and survey design. A web-based survey was created after incorporating feedback from this review process with a mechanism for participants to be randomly distributed between the food and waste surveys. A purposive approach was utilized in order to reach the targeted population of both current and developing K-12 teachers (justification is discussed in section 1.2$)^{1}$. Ultimately we received a total of 346 responses, 154 to the food survey, and 192 to the waste survey.

\subsection{Limitations of this Survey}

This survey design only measured the respondents' knowledge and behaviors at a static point in time. From this data alone we cannot conclude that an intervention (such as an education program) which increases an individual's knowledge in the different domains will correspondingly increase their participation in sustainable behaviors. Our survey enables us to examine the relationship between knowledge and behaviors and whether certain types of knowledge predict participation in behaviors but this survey on its own is not sufficient on its own to draw conclusions about interventions. In order to better evaluate the relationship between changes in the knowledge domains and changes in behavior a panel sample or other type of research design is needed. Additionally, the survey's quantification of subjective knowledge is not intended to yield precise measurements but rather to elicit broad patterns and relationships among a large population that would not be possible with the typical qualitative or case study approach to studying subjective knowledge.

\subsection{The Variables and Data Analysis}

The results from the surveys were loaded into SPSS (Statistical Package for the Social Sciences) v. 20.0 which was subsequently used for all the analysis. We calculated the Cook's distance- the most

\footnotetext{
${ }^{1}$ Professors teaching courses ranging from early childhood, history of teaching, technology and education, education policy, and science education, agreed to disseminate the survey to their students. To increase the sample size and diversity of teachers the survey was also sent out nationally via the National Science Teachers Association (NSTA) list-serv.
} 
widely used statistical test for measuring the influence of an individual observation (Kim \& Storer, 1996) — to discover which respondents exerted undue influence on the results. For the food survey, five respondents were found to be outliers with undue influence and therefore were removed; reducing the number of responses used in the data analysis to 149 . For the waste survey, six respondents were found to be outliers and were removed, making the final sample size for the waste survey 186.

In order to examine the knowledge domains as predictors of behavior, composite indices were created for each knowledge and behavior domain. This was done by calculating an individual's mean response to each group of questions (e.g., there were 11 questions which measured the respondent's declarative knowledge about food sustainability, and the mean of the answers to these questions was used to form the respondent's declarative knowledge index). When multiple questions are used to measure the same thing (e.g., knowledge in a given domain), as was done in this survey, these items should be correlated with one another (Bland \& Altman, 1997). For example, the way an individual answers one declarative food question should be consistent with the way they answer the other declarative food questions. As seen in Table 2, the composite scores for each domain were internally consistent and reliable based on the Cronbach's Alpha ${ }^{2}$.

Table 2.

Reliability measured by Cronbach's Alpha ( $\alpha)$ and means for knowledge domain and behavior indices

\begin{tabular}{|l|c|c|c|c|c|c|}
\hline \multirow{2}{*}{ Domain } & \multicolumn{3}{|c|}{ Food } & \multicolumn{3}{c|}{ Waste } \\
\cline { 2 - 7 } & $N$ & $\alpha$ & $\begin{array}{c}\text { Mean (standard } \\
\text { deviation) }\end{array}$ & $N$ & $\alpha$ & $\begin{array}{c}\text { Mean (standard } \\
\text { deviation) }\end{array}$ \\
\hline Declarative & 11 & 0.739 & $3.58(.53)$ & 11 & 0.768 & $3.78(.50)$ \\
\hline Procedural & 8 & 0.761 & $3.28(.72)$ & 7 & 0.813 & $3.38(.83)$ \\
\hline Effectiveness & 10 & 0.769 & $3.24(.56)$ & 12 & 0.766 & $3.58(.64)$ \\
\hline Social & 11 & 0.606 & $3.42(.47)$ & 9 & 0.749 & $3.55(.56)$ \\
\hline Behavior & 9 & 0.673 & $2.92(.50)$ & 9 & 0.764 & $3.38(.65)$ \\
\hline
\end{tabular}

\footnotetext{
${ }^{2}$ The Cronbach's alpha reliability coefficient normally ranges between 0 and 1 and the closer Cronbach's alpha coefficient is to 1.0 the greater the internal consistency of the items in the scale (Bland \& Altman, 1997).
} 
We collected standard demographic data such as gender, race, and age, as well as the respondents' political affiliation, state of residence, income, and whether or not they have ever taken a sustainability course (see Table 3). Researchers have found that gender, ethnicity, political orientation and income can impact sustainable values, attitudes, and behaviors (Gossard \& York, 2003; Larson et al., 2011), therefore it was necessary to account for the contribution these variables might have in predicting sustainable behaviors. Additionally, we controlled for home ownership and presence of household curbside recycling programs because other researchers have found that household commingled recycling programs increase participation in recycling and home ownership may impact other sustainable waste behaviors (i.e., composting) (Gamba \& Oskamp, 1994).

Descriptive statistics were calculated for all of the socio-demographic items for both the food and waste survey respondents. We compared the demographics of the respondents for this survey to demographic information collected by the National Center for Education on public school teachers in the United States (Feistrizer, 2011) and found our sample populations to be similar to the general population of teachers.

\section{Table 3.}

Overview of the control variables

\begin{tabular}{|c|c|c|c|}
\hline & $\begin{array}{l}\text { Food, } \\
\text { N=149 }\end{array}$ & $\begin{array}{l}\text { Waste, } \\
\mathrm{N}=186\end{array}$ & Type of Variable \\
\hline$\%$ Female & $60 \%$ & $66 \%$ & dichotomous \\
\hline$\%$ Anglo/White & $83 \%$ & $85 \%$ & dichotomous \\
\hline $\begin{array}{r}<30 \\
30-40 \\
40-50 \\
50+\end{array}$ & $\begin{array}{l}12 \% \\
25 \% \\
25 \% \\
38 \%\end{array}$ & $\begin{array}{l}9 \% \\
24 \% \\
28 \% \\
39 \%\end{array}$ & continuous \\
\hline Curbside Recycling (Yes) & & $73 \%$ & dichotomous \\
\hline House (Yes) & $79 \%$ & $86 \%$ & dichotomous \\
\hline Sustainability Course (Yes) & $14 \%$ & $15 \%$ & dichotomous \\
\hline Region of Residence (Yes- AZ) & $37 \%$ & $50 \%$ & dichotomous \\
\hline $\begin{array}{rr}\text { Political Orientations } & \\
& \text { Very Liberal } \\
\text { Liberal } \\
\text { Moderate }\end{array}$ & $\begin{array}{c}9 \% \\
32 \% \\
32 \%\end{array}$ & $\begin{array}{l}10 \% \\
27 \% \\
33 \%\end{array}$ & dichotomous \\
\hline
\end{tabular}




\begin{tabular}{|c|c|c|c|c|}
\hline & $\begin{array}{r}\text { Conservative } \\
\text { Very Conservative } \\
\text { Other }\end{array}$ & $\begin{array}{c}20 \% \\
1 \% \\
6 \%\end{array}$ & $\begin{array}{l}18 \% \\
4 \% \\
8 \%\end{array}$ & \\
\hline Income Under & $\begin{array}{r}\$ 20,000 \\
\$ 20,000-\$ 34,999 \\
\$ 35,000-\$ 59,999 \\
\$ 60,000-\$ 89,000 \\
\$ 90,000 \text { or more } \\
\text { Did Not Report }\end{array}$ & $\begin{array}{l}4 \% \\
11 \% \\
24 \% \\
26 \% \\
22 \% \\
13 \%\end{array}$ & $\begin{array}{c}3 \% \\
9 \% \\
25 \% \\
25 \% \\
27 \% \\
11 \%\end{array}$ & continuous \\
\hline
\end{tabular}

\section{Results}

We used ordinary-least squares (OLS) regressions to test our hypothesis that increased knowledge in procedural, effectiveness and social domains will predict increased participation in sustainable behaviors while increased declarative knowledge will not. The indices of the four knowledge domains were utilized as the independent variables, while the socio-demographic and other variables were included as controls. The overall sustainable behavior indices for food and waste were the main dependent variables analyzed but we also investigated the relationship of the knowledge domain indices with individual and sets of related behaviors. This model enables a straightforward interpretation of the regression results; the larger the coefficients for a knowledge domain index means the more important that domain is in predicting an individual's participation in sustainable behaviors (their behavior index score).

Except for a couple of cases discussed later in this section, the control variables were not significant in the OLS regressions and thus are not reported in the main body of the paper (see Appendix $\mathrm{B}$ for results including control variables). In addition to the standard analyses, we also looked at the Variance Influence Factor $^{3}$ (VIF) for each of the knowledge domain indices in order to assess multicollinearity. As can be seen in table 4, the VIF is below 4 for each index, indicating that the knowledge domains were not too closely inter-related to be utilized as independent variables.

\footnotetext{
${ }^{3}$ The Variance Inflation Factor (VIF) is a widely used measure for assessing multi-collinearity issues (O’Brien, 2007). Typically a VIF of 10 or even one as low as 4 have been used as rules of thumb to indicate serious multi-collinearity.
} 


\section{Table 4.}

OLS regression coefficients and standard errors for food and waste behavior indices

\begin{tabular}{|c|c|c|c|c|c|c|c|c|}
\hline \multirow{3}{*}{$\begin{array}{c}\begin{array}{c}\text { Independent } \\
\text { Variable }\end{array} \\
\text { Coefficients }\end{array}$} & \multicolumn{4}{|c|}{ Food Behaviors Index } & \multicolumn{4}{|c|}{ Waste behaviors Index } \\
\hline & \multicolumn{2}{|c|}{ Unstandardized } & \multirow{2}{*}{$\begin{array}{c}\text { Standardized } \\
\text { Beta }\end{array}$} & \multirow[b]{2}{*}{$V I F$} & \multicolumn{2}{|c|}{ Unstandardized } & \multirow{2}{*}{$\begin{array}{c}\text { Standardized } \\
\text { Beta }\end{array}$} & \multirow[b]{2}{*}{$V I F$} \\
\hline & B & $\begin{array}{l}\text { Std. } \\
\text { error }\end{array}$ & & & $B$ & $\begin{array}{l}\text { Std. } \\
\text { error }\end{array}$ & & \\
\hline $\begin{array}{l}\text { Declarative } \\
\text { Knowledge }\end{array}$ & .065 & .065 & .069 & 1.780 & -.120 & .068 & -.091 & 2.351 \\
\hline $\begin{array}{l}\text { Procedural } \\
\text { Knowledge }\end{array}$ & .195 & .063 & $.282 * *$ & 2.944 & .246 & .050 & $.313 * * *$ & 3.498 \\
\hline $\begin{array}{l}\text { Effectiveness } \\
\text { Knowledge }\end{array}$ & .108 & .077 & .122 & 2.621 & .308 & .063 & $.302 * * *$ & 3.317 \\
\hline $\begin{array}{l}\text { Social } \\
\text { Knowledge }\end{array}$ & .465 & .068 & $.437 *$ & 1.454 & .472 & .060 & $.404 * * *$ & 2.322 \\
\hline Adjusted $\mathrm{R}^{2}$ & & & .577 & & & & .787 & \\
\hline $\mathrm{F}$ & & & 7.807 & & & & 3.445 & \\
\hline $\mathrm{N}$ & & & 149 & & & & 186 & \\
\hline
\end{tabular}

In table 4 we report the OLS regression results for our principal model. Overall, the knowledge domain indices appear to be a fairly good model for predicting behaviors, with an adjusted $\mathrm{R}^{2}$ value of 0.577 for the food behavior regression and 0.787 for the waste behavior regression. It is interesting to note that both the $\mathrm{R}^{2}$ values and Cronbach's Alphas were higher for the waste knowledge domain indices and regressions as compared to those for food. Previous research has shown that food behaviors are more complex and difficult to change than waste behaviors (Redman, 2013). These results further bolster this finding, showing sustainable food behaviors to be harder to predict based on the knowledge domains as compared with waste behaviors. 
The results from these regressions support the basic hypothesis that we proposed when beginning this research. Declarative knowledge was not a statistically significant predictor of sustainable behaviors in either of these models (and had a standardized beta coefficient near zero). This means that having more declarative knowledge did not make a survey participant any more likely to participate in the relevant Sustainable behaviors. This provides further empirical evidence to the case for deemphasizing declarative knowledge when targeting individual behaviors. On the other hand the indexes we created to measure knowledge in the other three domains did predict participation in various sustainable behaviors. Procedural and social knowledge about food were significant, positive predictors of increased participation in sustainable food behaviors. On the waste side, increased procedural, effectiveness and social knowledge all predict increased sustainable behavior to the highest degree of statistical significance we measured $(\mathrm{p}<0.001)$. For both the food and waste regressions, increases in social knowledge indicated the largest predicted increases in sustainable behavior of any of the knowledge domains.

The food and waste behavior indices were constructed from a number of distinct behaviors that previous research indicated may have different drivers and benefits of action to the individual (e.g. people may eat less meat to reduce their carbon footprint and eat less processed foods for improved health). As such, we created behavior sub-indices based on theoretical categorization as well as correlations (Pearson's rho values between the individual behaviors). The indices created for food behaviors include (factors that represent the sustainable actions for each index are noted in parenthesis): 1.) meat eating behaviors (low levels of chicken and beef consumption and high frequency of meat-less meals), 2.) processed food purchasing (low levels of fast foods and pre-packaged food purchasing, and frequent purchasing of whole foods), and 3.) sustainable food purchasing (frequently purchasing organic or local foods). For waste we created three indices: 1.) recycling (frequently recycling at home and at 
campus/school), 2.) reducing waste through purchasing practices (purchasing products with less packaging, and products made from post-consumer materials and using reusable bags when checkingout at a store), 3.) reusing (frequently reusing bottles, napkins, and bags).

\section{Table 5.}

OLS regression coefficients for food and waste behaviors separated into like categories

\begin{tabular}{|c|c|c|c|c|c|c|}
\hline $\begin{array}{c}\text { Independent } \\
\text { Variable }\end{array}$ & $\begin{array}{c}\text { Meat eating } \\
\text { Index } \\
(n=3 \\
\alpha=.693)\end{array}$ & $\begin{array}{c}\text { Processed } \\
\text { Foods } \\
\text { Index } \\
(\mathrm{n}=3 \\
\alpha=.454) \\
\end{array}$ & $\begin{array}{c}\text { Sustainable } \\
\text { Food Index } \\
\quad(\mathrm{n}=3 \\
\alpha=.556)\end{array}$ & $\begin{array}{c}\text { Recycling } \\
\text { Index } \\
(\mathrm{n}=2, \\
\alpha=.767)\end{array}$ & $\begin{array}{c}\begin{array}{c}\text { Reduce } \\
\text { Index } \\
(\mathrm{n}=3, \\
\alpha=.652)\end{array} \\
\end{array}$ & $\begin{array}{c}\begin{array}{c}\text { Reuse } \\
\text { Index } \\
(\mathrm{n}=3, \\
\alpha=.532)\end{array} \\
\end{array}$ \\
\hline Mean (std) & $3.08(.64)$ & $3.22(.58)$ & $2.69(.69)$ & $4.29(.89)$ & $3.10(.80)$ & $3.37(.87)$ \\
\hline \multicolumn{7}{|c|}{ Coefficients: Standardized Beta } \\
\hline $\begin{array}{l}\text { Declarative } \\
\text { Knowledge }\end{array}$ & -.059 & .116 & .051 & -.142 & -.032 & -.011 \\
\hline $\begin{array}{l}\text { Procedural } \\
\text { Knowledge }\end{array}$ & $.301 *$ & .093 & .051 & -.048 & $.222 * *$ & $.234 *$ \\
\hline $\begin{array}{l}\text { Effectiveness } \\
\text { Knowledge }\end{array}$ & -.126 & .171 & $.274 * *$ & $.307 * *$ & $.233 * *$ & $.293 * * *$ \\
\hline $\begin{array}{l}\text { Social } \\
\text { Knowledge } \\
\end{array}$ & $.387 * * *$ & $.360 * * *$ & $.356 * * *$ & $.477 * * *$ & $.305 * * *$ & $.258 * * *$ \\
\hline Adjusted $\mathrm{R}^{2}$ & .229 & .315 & .365 & .415 & .604 & .548 \\
\hline $\mathrm{F}$ & 4.649 & 6.663 & 8.075 & 11.102 & 22.691 & 18.269 \\
\hline $\mathrm{N}$ & 149 & 149 & 149 & 185 & 185 & 185 \\
\hline
\end{tabular}

$* \mathrm{p}<0.05, * * \mathrm{p}<0.01, * * * \mathrm{p}<0.001$

As seen in Table 5, the knowledge domain indices predict less of the variation of these narrower behavior indices than for the overall behavior indices (as measured by the adjusted $\mathrm{R}^{2}$ values). Again, declarative knowledge was not a significant predictor of any of these behavior sub-indices. On the other hand, increased social knowledge was a highly statistically significant $(\mathrm{p}<0.001)$ predictor of increases for all six of the behavior indices tested here. Effectiveness knowledge was consistently a positive predictor for all the waste indices while procedural knowledge was found to be significant in predicting meat consumption, reducing and reusing behaviors. Another interesting result emerged from the 
recycling sub-index. The two behaviors which made up the index, frequency of recycling at home and recycling at school, were found to be significantly correlated to a greater extent than any other two behaviors $(\mathrm{rho}=.623 * *)$. This suggests a strong connection between behaviors done at school and behaviors done at home.

While in general the control variables included in this study were not statistically significant, in two cases particular variables proved revealing about the interplay between individual agency and structural issues. This research focuses on the agency of individuals to make behavioral changes in their lives which are essential for society to transition to sustainability. Yet there are serious structural constraints to achieving a sustainable transition solely through individual agency (e.g. government policy, existing infrastructure, available technology, etc.). In this case, the existence of recycling infrastructure (curbside recycling) is a very significant predictor of increased frequency of recycling (standardized beta $=.230, \mathrm{p}<0.001$ ), a result which shouldn't be surprising based on previous research (Gamba \& Oskamp, 1994), but reinforces the necessity of supportive structural systems. Similarly, frequency of purchasing local foods appears to be somewhat dependent on an individual's geographic location. Survey respondents who lived in Arizona were significantly less likely to purchase local food as often as the rest of the population (standardized beta=-.250, $\mathrm{p}<0.01$ ). The influence of geographic location on local food purchasing may be an indication of situational or structural constraints associated with the fact that Arizona's cities have fewer farmer's markets per capita than other comparable US cities (Jilcott et al., 2011).

\section{Discussion}

While there is variation in terms of how the knowledge domains interact with the individual behaviors, declarative knowledge is consistently not significant in terms of predicting participation in sustainable behaviors. Our finding that more declarative knowledge does not predict greater 
participation in sustainable behaviors for food or waste is in line with other studies that have found declarative knowledge to be mostly ineffective in promoting environmentally responsible behaviors (Kollmuss \& Agyeman, 2002; Pooley \& O'Connor, 2000a). The implication of this finding for sustainability education is that if we hope to foster transformative change, we must shift away from educational approaches that focus primarily on declarative knowledge. Additionally, this survey found no correlation between participating in a sustainability course and behaving sustainably, reaffirming that current sustainability education is not sufficiently influencing behaviors (most likely due to the focus on declarative knowledge).

In spite of our critiques of declarative knowledge, there is still clearly a place for technical, ecological information in our education system (DuPuis \& Ball, 2013). Even though our analysis indicates that declarative knowledge does not predict participation in sustainability-related behaviors, this form of knowledge is still a critical component of sustainability literacy (Monroe, 2003). Additionally, some researchers have suggested that very low amounts of declarative knowledge may form a barrier to action (Kaiser \& Fuhrer, 2003; Monroe, 2003). All of our surveyed population was at least in the process of obtaining their undergraduate degree (and many were enrolled or had completed masters and PhD programs) in addition to having made a lifelong commitment to education (as K-12 teachers). We would therefore expect that the mean knowledge domain index scores were substantially higher than would be found among a general population survey, particularly for declarative knowledge (mean scores for food survey=3.58, waste=3.78). The high levels of declarative knowledge among participants may have impeded this study from finding a significant negative impact on sustainable behaviors for those with very low levels of declarative knowledge.

The positive and significant impact that procedural, effectiveness, and social knowledge had on predicting an increase in participation of sustainable behaviors (particularly in contrast to declarative 
knowledge) demonstrates the need to incorporate diverse domains of knowledge into our education strategies. In particular, social knowledge appears to be critical across a wide array of behaviors. In developing strategies for targeting social knowledge, sustainable behaviors should be positively reinforced and positioned as 'normal' and 'desirable.' One way to do this is through consciously modeling sustainable behaviors in the classroom and building sustainable practices into everyday operations at schools. By building sustainable practices (such as composting) into the classroom, students and teachers can gain the necessary knowledge regarding how-to compost (procedural knowledge), while creating a norm of behaving sustainably at school, thus, also increasing social knowledge. Integrating practices in schools that enhance knowledge in the relevant domains is not only critical to promoting sustainable behaviors, but also central to moving beyond surface knowledge regarding sustainability.

In exploring the relationships between the knowledge domains and specific behaviors, it is clear that the knowledge domains interact differently with different behaviors. Composting really stood out as its variance was almost completely predicted by the level of procedural knowledge (standardized beta $=.623, \mathrm{p}<0.001$ ), while the other knowledge domain indexes had no significant predictive impact on this particular behavior. This finding suggests that there are different barriers, drivers, and motivations associated with specific behaviors. For composting, lack of procedural knowledge regarding the establishment and maintenance of the system would clearly be a barrier to engaging in composting. In contrast, the purchasing of local foods was highly influenced by social knowledge regarding the desirability of going to farmer's markets. The direct interaction and feedback at farmer's markets made respondents feel 'good' about purchasing local food (mean response=4.1). The 'good' feeling about purchasing local food does not, however, spill over into the closely related behavior of purchasing organic food in a grocery store. These findings reinforce other researchers' positions regarding the 
importance of societal interactions as strong motivators for purchasing local foods (Stagl, 2002), whereas many people purchase organic food more for personal health reasons (Padel \& Foster, 2005).

While analysis revealed significant variation between individual behaviors, there were clearly more similarities within the food behaviors and waste behaviors than between them. Effectiveness knowledge, for example, was a significant predictor for eight of the nine waste behaviors but only a couple of the food behaviors. The immediate benefits of choosing sustainable food behaviors are far less direct and far more opaque than for waste behaviors. The lack of highly visible, short-term benefits regarding sustainable food consumption may contribute to the low importance of effectiveness knowledge for predicting food behaviors.

\section{Conclusion}

There is little doubt that progressing towards sustainability will require major political, technological, and other structural changes, but on its own these will be insufficient if individuals do not change as well (e.g., adopt and properly utilize the new technologies or practices). This paper stresses the importance of understanding how individuals perceive the practices and ideas being presented as sustainability solutions. In this research, we emphasized that in addition to the traditional, factual approach to knowledge (declarative and procedural); there are subjective types of knowledge (effectiveness and social) which, as with the nature of subjectivity in general, changes with local and cultural variations in perceptions, beliefs, and desires. The dynamic nature of knowledge was also demonstrated by the finding that different forms of knowledge interact differently with various behaviors, clearly indicating that the knowledge-behavior relationship is not static, nor universal. The diverse relationship between different knowledge domains and behaviors indicates that a combination of different approaches is needed in order to effectively educate for sustainability. Understanding this dynamic interplay between knowledge and behaviors will help sustainability advocates tailor education 
programs as well as marketing campaigns and product packaging in order to target the motivators and barriers to change.

While this research advanced the use of a multi-dimensional conceptualization of knowledge, each knowledge domain, particularly the subjective domains of knowledge (social and effectiveness) should be explored further. In terms of social knowledge, future sustainability research is needed to investigate the degree to which an individual is influenced by their perception of what their friends and family view as positive or negative, an important aspect of social knowledge which was not looked into by this study. In order to assess this type of social knowledge, questions need to be asked about what the respondent thinks their friends/family do, how much they care about what their friends and family do, and how close their perceptions are to reality. Other studies (on behaviors such as alcohol consumption) have shown that not only are individuals influenced by family and friends differently but also their perception of their peer environment varies from reality (Perkins, 2002). Examining the relationships amongst perception, reality, and peers versus family influence in terms of specific sustainable behaviors, especially given the overall importance of social knowledge revealed by the results presented here, is a critical future step.

K-12 teachers were chosen as the target population for this research based in a large degree on the assumption that teachers can help shape the future of tomorrow by modeling behaviors, establishing norms and imparting both subjective and technical knowledge to their students. However, the student/teacher relationship itself was not the focus of the research conducted here. Further research is needed to explore the relationship between teachers' knowledge and behaviors and how that translates into the classroom and influences the students by either simultaneously surveying teachers and their students or by taking a more intensive, case study approach. 
Investigations on how to motivate changes in individuals' behaviors that are necessary for a sustainable future are still in early phases, and significant research is needed to better untangle the relationship between the knowledge domains and sustainable behaviors. However, the results of this research, that non-declarative forms of knowledge are important to fostering sustainable behaviors among individuals, is hopefully a step in the right direction which can be built upon by further work and applied in ways which foster the needed transition to sustainability. 


\section{References}

Ajzen, I. (1985). From Intentions to Actions: a theory of planned behavior. In J. Kuhl, Beckmann, J. (Ed.), Action-Control: from cognition to behavior (pp. 11-39). Heidelberg: Springer.

Barr, S., Gilg, A., \& Ford, N. (2005). Defining the multi-dimensional aspects of household waste management: A study of reported behavior in Devon. Resources, Conservation and Recycling, 45(2), 172-192.

Bland, J. M., \& Altman, D. G. (1997). Statistics notes: Cronbach's alpha. BMJ, 314(7080), 572.

Cialdini, R. B., Reno, R. R., \& Kallgren, C. A. (1990). A focus theory of normative conduct: Recycling the concept of norms to reduce littering in public places. Journal of Personality and Social Psychology, 58(6), 1015-1026.

Cortese, A. (2003). The Critical Role of Higher Education in Creating a Sustainable Future. Planning for Higher Education(March-May), 15-22.

DuPuis, E., \& Ball, T. (2013). How not what: teaching sustainability as process. Sustainability: Science, Practice, \& Policy, 9(1), 64-75.

Eriksson, O., Carlsson Reich, M., Frostell, B., Björklund, A., Assefa, G., Sundqvist, J. O. \& Thyselius, L. (2005). Municipal solid waste management from a systems perspective. Journal of Cleaner Production, 13(3), 241-252.

Feistrizer, E. (2011). Profile of Teachers in the US 2011. National Center for Education Information.

Freeman, A. (2013). America's Coolest Green Schools. http://www.takepart.com/photos/green-schoolsAmerica. Accessed on April 4, 2013.

Frisk, E., \& Larson, K. L. (2011). Educating for Sustainability: Competencies \& Practices for Transformative Action. Journal of Sustainability Education, 2.

Funtowicz, S., \& Ravetz, J. (2003). Post-normal science. International Society for Ecological Economics. Retrieved from http://korny10.bke.hu/angol/ravetz2003.pdf

Gamba, R. J., \& Oskamp, S. (1994). Factors Influencing Community Residents' Participation in Commingled Curbside Recycling Programs. Environment and Behavior, 26(5), 587-612.

Gossard, M. H., \& York, R. (2003). Social Structural Influences on Meat Consumption. Human Ecology Review, 10(1), 1.

Heller, M. C., \& Keoleian, G. A. (2003). Assessing the sustainability of the US food system: a life cycle perspective. Agricultural Systems, 76(3), 1007-1041.

Hungerford, H. R., \& Volk, T. L. (1990). Changing learner behavior through environmental education. Journal of Environmental Education, 21(3), 8-22. 
Jilcott, S. B., Keyserling, T., Crawford, T., McGuirt, J. T., \& Ammerman, A. S. (2011). Examining Associations among Obesity and Per Capita Farmers' Markets, Grocery Stores/Supermarkets, and Supercenters in US Counties. Journal of the American Dietetic Association, 111(4), 567572.

Joseph, K. (2006). Stakeholder participation for sustainable waste management. Habitat International, 30(4), 863-871.

Kaiser, F. G., \& Fuhrer, U. (2003). Ecological Behavior's Dependency on Different Forms of Knowledge. Applied Psychology, 52(4), 598-613.

Kates, R. W., \& Parris, T. M. (2003). Long-term trends and a sustainability transition. Proceedings of the National Academy of Sciences, 100(14), 8062-8067.

Kelder, S. H., Perry, C. L., Klepp, K.-I., \& Lytle, L. L. (1994). Longitudinal tracking of adolescent smoking, physical activity, and food choice behaviors. American Journal of Public Health, 84(7), 1121-1126.

Kim, C., \& Storer, B. E. (1996). Reference values for cook's distance. Communications in Statistics Simulation and Computation, 25(3), 691-708.

Kollmuss, A., \& Agyeman, J. (2002). Mind the Gap: Why do people act environmentally and what are the barriers to pro-environmental behavior? Environmental Education Research, 8(3), 239-260.

Larson, K. L., Wutich, A., White, D., Muñoz-Erickson, T. A., \& Harlan, S. L. (2011). Multifaceted Perspectives on Water Risks and Policies: A Cultural Domains Approach in a Southwestern City. Human Ecology Review, 18(1), 75-87.

Leiserowitz, A., Kates, R. W., \& Parris, T. M. (2005). Do Global Attitudes and Behaviors Support Sustainable Development. Environment: Science and Policy for Sustainable Development, 47(9), 22-38.

Luepker, R., Johnson, C. A., Murray, D., \& Pechacek, T. (1983). Prevention of cigarette smoking: Three-year follow-up of an education program for youth. Journal of Behavioral Medicine, 6(1), 53-62.

McKenzie-Mohr, D. (2000). New Ways to Promote Proenvironmental Behavior: Promoting Sustainable Behavior: An Introduction to Community-Based Social Marketing. Journal of Social Issues, 56(3), 543-554.

McKenzie-Mohr, D. (2011). Fostering Sustainable Behavior: An Introduction to Community-Based Social Marketing: New Society Publishers.

Monroe, M. (2003). Two Avenues for Encouraging Conservations Behaviors. Human Ecology Review, 10(2), 113-125.

Moore, J. (2005). Is Higher Education Ready for Transformative Learning? Journal of Transformative Education, 3(1), 76-91. 
Nolet, V. (2009). Preparing Sustainability-Literate Teachers. Teachers College Record: The Voice of Scholarship in Educations, 111(2), 409-442.

O’Brien, R. (2007). A Caution Regarding Rules of Thumb for Variance Inflation Factors. Quality \& Quantity, 41(5), 673-690.

Orr, D. (1991). What is Education for? The Learning Revolution (Ic\#27) (pp. 52-59): Context Institute.

Padel, S. \& Foster, C. (2005) Exploring the gap between attitudes and behaviour: Understanding why consumers buy or do not buy organic food. British Food Journal, 107(8), 606 - 625.

Perkins, H. W. (2002). Social Norms and the Prevention of Alcohol Misuse in Collegiate Contexts. Journal of Studies on Alcohol. Supplement(14), 164-172.

Pooley, J. A., \& O’Connor, M. (2000a). Environmental Education and Attitudes. Environment and Behavior, 32(5), 711-723.

Pooley, J. A., \& O'Connor, M. (2000b). Environmental Education and Attitudes: Emotions and Beliefs are What is Needed. Environment and Behavior, 32(5), 711-723.

Ramsey, J. M. (1993). The effects of issue investigation and action training on eighth-grade students' environmental behavior. Journal of Environmental Education, 24(3), 31-36.

Redman, E. (2013). Advancing Educational Pedagogy for Sustainability: Developing and Implementing Programs to Transform Behaviors. International Journal of Environmental and Science Education. 4(1), 1-34.

Rogers, E. M. (2003). Diffusion of Innovations: Simon and Schuster.

Rowe, D. (2007). Education for a Sustainable Future. Science, 317(5836), 323-324.

Schultz, P. W., Nolan, J. M., Cialdini, R. B., Goldstein, N. J., \& Griskevicius, V. (2007). The Constructive, Destructive, and Reconstructive Power of Social Norms. Psychological Science, $18(5), 429-434$.

Simmons, B., \& Volk, T. (2002). Conversations with Environmental Educators: a conversation with Harold Hungerford. International Journal of Sustainability in Higher Education, 9(1), 68-86.

Stagl, S. (2002). Local Organic Food Markets: Potentials and Limitations for Contributing to Sustainable Development. Empirica, 29(2), 145-162.

Sterling, S. R. (2001). Sustainable education: re-visioning learning and change: Green Books for the Schumacher Society.

Stern, P. (1999). Information, Incentives, and Proenvironmental Consumer Behavior. Journal of Consumer Policy, 22(4), 461-478.

Stern, P. (2000). New Environmental Theories: Toward a Coherent Theory of Environmentally Significant Behavior. Journal of Social Issues, 56(3), 407-424. 
Stir, J. (2006). Restructuring teacher education for sustainability: student involvement through a "strengths model". Journal of Cleaner Production, 14(9-11), 830-836.

Trumbo, C. W., \& O'Keefe, G. J. (2001). Intention to Conserve Water: Environmental Values, Planned Behavior, and Information Effects. A Comparison of Three Communities Sharing a Watershed. Society and Natural Resources, 14(10), 889-899.

Tucker, P., \& Speirs, D. (2003). Attitudes and Behavioural Change in Household Waste Management Behaviours. Journal of Environmental Planning and Management, 46(2), 289-307.

Wright, B. (2000). Environmental NGOs and the Dolphin-Tuna Case. Environmental Politics. 9(4), 82103.

Zelezny, L. (1999). Educational Interventions that Improve Envrionmental Behaviors: a meta-analysis. The Journal of Envrionmental Education, 31(1), 5-14. 